\title{
THE ROLE OF EXPECTATIONS IN STABILIZATION POLICY*
}

\author{
Marianne BAXTER* \\ University of California, Santa Barbara, CA 93106, USA
}

\begin{abstract}
This paper develops and tests a theory of the process by which private agents in an economy form expectations about government policy. Agents form and update their beliefs about the true state of government policy in a Bayesian fashion. The 'credibility' of a policy is defined to be the subjective probability that the government is pursuing a 'reform' policy rule. The 'credibility' of a reform of monetary or exchange rate policies is a function of the parameters of both monetary and fiscal policies. The theory is applied to the Chilean and Argentine exchange reforms of the late 1970's.
\end{abstract}

\section{Introduction}

The fact that credibility matters greatly to the outcome of policy is wellknown: policymakers wishing to implement stabilization policies intended to reduce the inflation rate usually make well-publicized, emphatic announcements to that effect. Their aim is to reduce expectations of future inflation, and thereby reduce the real costs of deflation. It has been shown that a decrease in expectations of future inflation can cause a decrease in the current inflation rate via, for example, the incorporation of reduced inflationary expectations into current wage and price agreements. ${ }^{1}$ Hence, if announcements can influence expectations of future inflation, they can enhance the inflation-reducing effects of the stabilization policy.

But rational agents need more than mere announcements of reform in order to be convinced that they should revise their expectations about future government policies and future inflation rates. They will use all available information on current and past government policies to assess the probability that the reform can and will be carried out as announced. There has been,

*Visiting at the Department of Economics, University of Minnesota, Minneapolis, MN 55455 , during the 1984-1985 academic year.

* This paper is based on my University of Chicago doctoral dissertation. I wish to thank Robert E. Lucas, Jr., who suggested this research, and provided abundant help and encouragement. Thanks are also due to Arnold Zellner for many helpful discussions which materially influenced the direction of this work, and to participants of the Econometrics Workshop at UCSB, the International Trade Workshop at UCLA, and an anonymous referee. Any remaining errors are my own.

\footnotetext{
${ }^{1}$ See, for example, Sargent and Wallace (1981), Flood and Garber (1980), La Haye (1980), and Sargent (1981a,b).
} 
however, relatively little research devoted to the problem of modeling or measuring empirically the 'credibility' of macroeconomic policies.

This paper develops and implements a method for measuring the 'credibility' of an announced policy reform. Agents in the economy learn about the government's policy rules and calculate, using Bayesian techniques, the probabilities that these rules belong to a set of 'reform' rules. ${ }^{2}$ Thus, 'credibility' is defined to be the subjective probability, as assessed by agents in the economy, that a reform has in fact taken place. This definition of credibility is sufficiently general as to be applicable to any economic policy, as will be the method for actual calculation of a measure of credibility. However, the primary focus of this paper will be the evaluation of the credibility of policies aimed at reducing inflation via restrictive monetary policy. Empirical measures of credibility are constructed for the recent reforms in Chile and Argentina, in order to investigate the hypothesis that 'credibility' played an important part in determining the outcomes of these reforms.

\section{The recent experiences of Chile and Argentina}

In the late 1970's, both Chile Argentina were confronted with the dual problem of near-hyperinflations accompanied by large fiscal deficits financed at the Central Bank. Both, consequently, announced thorough-going stabilization policies, the cornerstone in each case being a preannounced exchange rate 'table'. The idea was to break inflationary expectations by announcing in advance an exchange rate path that entailed a decreasing rate of devaluation. It was hoped that confidence in the reform would be built up month by month as the announced exchange rates we successfully maintained, and that the increased confidence in the reform would provide an 'expectations bonus' in terms of reduced inflationary expectations and a consequent reduction in current inflation.

In Chile, the stabilization policy was a qualified success. After nineteen months of decelerating inflation, Chile fixed her exchange rate. The rate remained fixed for three years; Chile has since returned to a system of a managed float. Inflation is rising, and unemployment is still a serious problem, with unemployment rates estimated at $25 \%$ of the workforce.

In Argentina the policy was, from the beginning, much less successful. An unscheduled devaluation of only $10 \%$ which occurred about two years after the beginning of the reform shattered public confidence in the government's commitment to the policy and caused a run on Argentina's reserves. Further devaluations and capital flight followed, and at the present time Argentina is

\footnotetext{
${ }^{2} \mathrm{~A}$ closely related model for crawling peg regimes has been developed by Van Wijnbergen (1983).
} 
on a managed floating rate regime, while the fiscal deficit and rate of inflation exceed their levels at the time of the implementation of the stabilization policy.

How could two seemingly identical policies produce such different results? Part of the answer may be contained in the fact that Chile, about three years prior to the announcement of the exchange rate 'table', had instituted fiscal reform and had greatly reduced the rate of growth of the money supply. In Argentina, however, the fiscal deficit remained at roughly 5\% of GNP throughout the 'reform' period. The large fiscal deficit is widely thought to have injured the credibility of the reform, since it would have been impossible for the low levels of monetary growth and inflation implied by a stable exchange rate to generate enough seigniorage to finance the large government deficit.

This paper develops a model that emphasizes the link between monetary and fiscal policies and the importance of expectations in explaining these episodes. An implication of the theory developed in this paper is that rational agents will look beyond exchange rates at the total government policy 'package' of monetary and fiscal policies. The empirical results suggest that the difference in the outcomes of the Chilean and Argentine reforms may be explained, at least in part, by the fact that the Chilean reform was 'credible', while the Argentine reform was not.

\section{A theory of 'credibility'}

The application of the rational expectations hypothesis to the analysis of macroeconomic policy has led to a revolution in the way both economists and policymakers think about policy and its effects. Specifically, much more attention is now given to modelling people's reactions to changes in policy. It is in this way that the problem of 'credibility' arises, since a model that incorporates expectations cannot be solved without specifying exactly how these expectations are formed.

Consider the problem of how, at the time of an announcement of a change or 'reform' in some government policy, agents decide whether to believe that the reform will actually be carried out. At the time the reform is announced, people have only the past track record of the administration on which to form their expectations of the actual future course of policy. In the language of Bayesian statistical theory, people have a 'prior' on the parameters of the government policy rules. As time passes, people incorporate information contained in the realizations of the policy variables into their forecasts of the future path of policy. That is, agents combine realizations of the policy with their prior in order to form a posterior distribution on the policy parameters, which is used to make forecasts of future policy.

The 'credibility' of a reform is defined to be the posterior probability that the government is following the announced 'reform' policy rule. Since the 
government must operate within a budget constraint, we argue that a 'credible' monetary reform depends on a compatible fiscal policy. Rational individuals will use information contained in fiscal policy in attempting to assess the 'credibility' of a monetary reform; it is via these expectations channels that fiscal policy influences the success of a monetary reform.

\subsection{Fiscal policy and the feasibility of monetary reform}

A 'feasible' reform is defined to be a system of policy rules which satisfies the following two conditions:

(i) the rate of expansion of the domestically controlled component of the money supply is reduced (as announced), and

(ii) financing the fiscal deficit does not imply an explosive path for the real value of interest-bearing government debt.

Condition (i) ensures that the announced exchange or monetary policy can be sustained in the long run, and therefore can reduce the long-run inflation rate. The exact constraints on the monetary authority depends on the exchange regime chosen.

In the cases of Chile and Argentina; it was announced that the rate of devaluation would decrease over time, according to a specified 'table', with the intention of fixing the exchange rate in the near future. The decision to target the exchange rate constrains the choice of a monetary policy. Since purchasing power parity is a condition that must hold in long-run equilibrium, in the long run it will be true that $\pi=\pi^{*}+\hat{e}$, where $\pi$ is the domestic inflation rate, $\pi^{*}$ is the foreign inflation rate, and $\hat{e}$ is the rate of devaluation. If the exchange rate is fixed, $\hat{e}$ is zero, and the domestic inflation rate equals the foreign rate. The rate of growth of domestically created money, $\theta$, will not, in general, be equal to the rate of growth of the nominal money supply, which is demanddetermined under a fixed exchange rate regime. If $\theta>\pi^{*}$, in the long run there will be a (domestically created) excess supply of money, leading to continual reserve outflows, and the authorities will eventually be forced to abandon the fixed rate regime. It is in this sense that the choice of an exchange rate path constrains the choice of a monetary policy: a fixed rate regime requires that the monetary authority choose $\theta \leq \pi^{*}$. During the transition period, when there is a positive but diminishing rate of devaluation, the government could, if it chose, expand domestic credit at a rate exceeding $\pi^{*}$, without jeopardizing the long-run success of the reform. However, we define a 'credible' monetary policy to be one that chooses $\theta<\pi^{*}$ in every time period. This has the implication that what matters to private agents in the economy is whether the currently observed policy is sustainable in the long run.

Condition (ii) prohibits the government from running a Ponzi scheme with its debt. Since there is an upper bound on the present value (in real terms) of 
future tax collections, the government will not be able to sell claims on future taxes (i.e., debt) in excess of that bound. It is therefore necessary that the time path for real government debt be non-explosive.

We shall assume that government policies can be described by linear feedback rules. Different 'policies' are distinguished by different parameters, but not different functional forms for these rules. We shall assume that the set of all possible policies (or, equivalently, policy parameters) may be broken into two complementary sets: the sets of 'reform' (R) and 'non-reform' (NR) policies. The problem facing agents in the economy is to assign a probability to the event that the current policy regime belongs to the reform set, and to form estimates of the parameters of the government policy rules, for the purpose of forecasting future values of the policy variables. Over time, as they observe more realizations of the policy variables, agents can form increasingly sharp estimates of the true policy parameters, assuming, of course, that these parameters do not change over time.

Let the rule for 'monetary policy' be given by

$$
D C_{t}=\left(1+\theta+\varepsilon_{t}\right) D C_{t-1} \text {, }
$$

where $D C_{t}$ is the level of domestic credit (the domestically created component of the monetary base), $\theta$ is the target rate of growth of $D C$, and $\varepsilon$ is an i.i.d. error term with mean zero and variance $\sigma_{e}^{2}$. Let the policy rule for the government deficit be given by

$$
D_{t}=\alpha_{0}+\alpha_{1} B_{t-1}+u_{t}
$$

where $D_{t}$ is the real value of the government deficit at time $t$, exclusive of debt service, $B_{t-1}$ is the real value of outstanding government debt at time $t-1$, and $u_{t}$ is an i.i.d. error term with mean zero and variance $\sigma_{u}^{2}$. The government's budget constraint is given by

$$
D_{t}=B_{t}-(1+R) B_{t-1}+\left(D C_{t}-D C_{t-1}\right) / p_{t} \text {, }
$$

where $R$ is the one-period real rate of interest, assumed constant, and $p_{t}$ is the period $t$ price level. Combining (2) and (3), we obtain a first-order difference equation in real debt:

$$
B_{t}=\alpha_{0}+\left(1+R+\alpha_{1}\right) B_{t-1}-\left(D C_{t}-D C_{t-1}\right) / p_{t}+u_{t} .
$$

In the long run, purchasing power parity will hold, so that an open economy with a fixed exchange rate will have an inflation rate, $\pi$, equal to the world 
inflation rate, $\pi^{*}$. Using this fact together with eq. (1), (4) becomes

$$
B_{t}=\alpha_{0}+\gamma B_{t-1}-\frac{\theta}{1+\pi^{*}}\left(\frac{1+\theta}{1+\pi^{*}}\right)^{t-1}\left(\frac{D C_{0}}{p_{0}}\right)+\xi_{t}
$$

where $\xi_{t}$ is an error term involving both $u_{t}$ and $\varepsilon_{t}, \varepsilon_{t-1}, \cdots, \varepsilon_{1}$, and $\gamma=(1+R$ $+\alpha_{1}$ ). If $\gamma<1$ and $\theta \leq \pi^{*}$, eq. (5) is stable, and condition (ii) for feasibility is satisfied.

Recall that we needed $\theta \leq \pi^{*}$ for condition (i) to be satisfied. This ensures that domestically created monetary growth is low enough so that, in the long run, equilibrium in the money market does not entail continual reserve outflows. The condition $\gamma<1$ implies that $\alpha_{1}<-R$, which means [from (2)] that the government has a policy which retires some of the principal of the debt each period. If there is real growth in the economy, this condition is the correct one if the variables in (5) are normalized by dividing by the period $t$ level of output.

Any reform of monetary policy will, in order to be considered 'credible', have to be 'feasible' in the sense of satisfying (i) and (ii) above. Therefore, a correct measure of credibility for an announced monetary reform must include both monetary and fiscal variables.

\subsection{Measuring credibility}

The problem facing private agents is to infer the parameters of the government policy rules, given observation of past realizations of the policy variable. This problem has a natural Bayesian interpretation as it involves the principle of 'inverse probability', where the data are taken as given and the problem is to try to infer what random process generated them.

Suppose the government announces at time $t=0$ its intention to follow a 'reform' policy rule beginning at time $t=1$. We shall assume that government policies may be written in the familiar form of the linear multiple regression model:

$$
y=\boldsymbol{X}^{\prime} \boldsymbol{\theta}+u,
$$

where $y$ is the policy's 'target' variable, $X$ is a $k \times 1$ vector of state variables, $\theta$ is a $k \times 1$ vector of regression coefficients, and $u$ is an error term, assumed independently and identically normally distributed with mean zero and variance $\sigma^{2}$. Announcement of a reform amounts to announcement of a parameter vector, $\theta^{*}$, which will be used beginning at $t=1$ to target policy variable $y$ according to eq. (6).

At $t=0$, the date of the announcement of reform, individuals in the economy have some 'prior beliefs' about the true future value of $\theta$. Agents' 
priors for $\theta$ and $\sigma$ are assumed to be summarized by a prior p.d.f. of the natural conjugate form. The certainty with which they hold these prior beliefs is captured by the prior variance-covariance matrix for $\theta$. Combining the prior p.d.f. with the likelihood function for the post-reform realizations of the policy variables yields the posterior p.d.f. 'Rational' agents with a symmetric loss function will use the mean of this posterior distribution, $\tilde{\theta}_{t}$, which depends on both sample and prior information, to make predictions about the future course of policy. In the case where agents' prior beliefs about $\theta$ are quite diffuse, the government can quickly and directly affect expectations by means of strict adherence to its announced 'reform' policy rule, since this will cause the posterior mean, $\tilde{\theta}_{t}$, to converge quickly to the announced value, $\theta^{*}$.

The problem facing agents in the economy is that of assigning a probability to the event that the current policy regime belongs to the reform (R) set. Letting $f\left(\theta \mid y_{t}\right)$ denote the marginal posterior p.d.f. for $\theta$, given the vector of observations of the policy variable $y_{t}$, the 'credibility' of reform in period $t, C_{r}$, is given by

$$
C_{t}=\int_{\theta \in R} f\left(\theta \mid y_{t}\right) \mathrm{d} \theta
$$

Once the 'credibility' variable has been constructed, we shall compare the time path of 'credibility' to those economic variables theory suggests are affected by expectations. If the underlying economic theory is correct, if people form expectations 'rationally', and if we have included all the relevant $\theta_{i}$ in $\theta$, then we should observe empirically that a more 'credible' policy of reducing the monetary growth rate is accompanied by a higher level of real cash balances, and lower current inflation and interest rates. That is, we expect to observe a positive covariance between $C_{t}$ and real balances at time $t$, and negative covariances between $C_{t}$ and period $t$ inflation and interest rates. This analysis may be usefully construed as a way of ascertaining what variables under the government's control matter most to 'credibility', in the sense of yielding the predicted covariance. It may also be viewed as a means for understanding the nature of people's prior beliefs and their role in determining the outcome of policy since, theoretically, we could work backward from data on people's reactions to observed policy to infer what prior p.d.f. could have generated these data.

\section{Estimation of 'credibility': Application to Chile and Argentina}

This section applies the methods developed in section 2 to the Chilean and Argentine reforms of the late 1970's, in order to determine whether there is empirical support for the hypothesis that expectations played an important part in determining the outcomes of these two reforms. 
All the steps of the estimation were undertaken under a variety of assumptions about the prior p.d.f., in order to ascertain how variations in prior beliefs affect the 'credibility' of realized sequences of the policy variables. The Bayesian regression package $\mathrm{BRAP}^{3}$ was used to perform the estimation.

Recall that a feasible reform must satisfy the two conditions:

(i) $\theta \leq \pi^{*}$, which ensures that the fixed exchange rate can be maintained in the long run, and that inflation will be reduced, and

(ii) $\gamma<1$, which, together with (i), ensures that the debt path is non-explosive.

The two conditions are independent, since the choice of $\theta$ does not constrain the choice of $\gamma$. For every $\theta$, the government can choose any deficit path it likes (i.e., any $\gamma$ ). This combination of monetary and fiscal policies may or may not be 'feasible' in the sense of satisfying the two conditions above, but there is nothing to prevent either the monetary or the fiscal authority from embarking on whatever policy it chooses. In this sense, then, the choices of $\theta$ and $\gamma$ are independent.

The estimate of $\theta$ is obtained from estimation of eq. (1), reproduced below:

$$
D C_{t}=\left(1+\theta+\varepsilon_{t}\right) D C_{t-1} .
$$

Eq. (2), reproduced below, was used to estimate $\gamma$ :

$$
B_{t}=\alpha_{0}+\gamma B_{t-1}-\frac{D C_{t}-D C_{t-1}}{p_{t}}+u_{t}
$$

Since we know that the coefficient of $\left[D C_{t}-D C_{t-1}\right] / p_{t}$ must be one, we can constrain it by forming the variable $B_{t}^{*}=B_{t}+\left[D C_{t} D C_{t-1}\right] / p_{t}$, and run the regression

$$
B_{i}^{*}=\alpha_{0}+\gamma B_{t-1}+u_{i}
$$

Although there is no necessary covariance between the rules for monetary and fiscal policy, it may exist. Zellner's method of 'seemingly unrelated regressions' was used to test for such covariance: none was found. Since interdependence of monetary and fiscal policies is neither implied by the theory nor found in the data, we assume that the joint probability that both conditions are satisfied, $\operatorname{pr}\left(\theta<\pi^{*}, \gamma<1\right)$, is equal to $\operatorname{pr}\left(\theta<\pi^{*}\right) \operatorname{pr}(\gamma<1)$. The posterior p.d.f.'s for $\theta$ and $\gamma$ were calculated over the reform period for several sets of prior assumptions: the parameters of the various prior p.d.f.'s for $\theta$ are given in table 1.

\footnotetext{
${ }^{3}$ This package allows the user to specify the prior p.d.f., and combines the sample data with the prior to produce a posterior p.d.f..
} 
Table 1

Monetary policy: Parameters of prior p.d.f.'s.

\begin{tabular}{|c|c|c|c|c|c|}
\hline Prior & $\theta_{0}$ & $A$ & $s_{0}^{2}$ & $v_{0}$ & $\begin{array}{l}\text { Prior probability } \\
\text { of feasible } \\
\text { monetary policy }\end{array}$ \\
\hline \multicolumn{6}{|c|}{ Argentina } \\
\hline 1 & \multicolumn{5}{|c|}{ diffuse prior } \\
\hline 2 (disbelievers) & $0.0115^{5}$ & 12 & 0.0022 & 11 & 0.445 \\
\hline 3 (believers) & 0.0095 & 12 & 0.0022 & 11 & 0.500 \\
\hline \multicolumn{6}{|c|}{ Chile } \\
\hline 1 & \multicolumn{5}{|c|}{ diffuse prior } \\
\hline 2 (disbelievers) & 0.0607 & 12 & 0.0016 & 11 & 0.001 \\
\hline 3 (believers) & 0.0095 & 12 & 0.0016 & 11 & 0.500 \\
\hline
\end{tabular}

All priors are of the natural-conjugate type, with the normal p.d.f. for $(\theta \mid \sigma)$ having mean $\theta_{0}$ and variance $A^{-1} \sigma_{\varepsilon}^{2}$, and the inverted gamma for $\sigma_{\varepsilon}$ having mean $s_{0}$ and $v_{0}$ degrees of freedom. Prior 1 is a diffuse prior. Prior 2 is a 'data-based' prior, and is based on realizations of the policy variable $\theta$ for the twelve months prior to the reform date. Thus, the mean monthly rate of growth of domestic credit $(D C)$ in Argentina over the twelve months preceding the reform date was 0.0115 (about one percent per month). The mean monthly growth rate of domestic credit was 0.0607 in Chile over the twelve months preceding the reform date. Agents with prior 2 may be thought of as not believing the reform will take place: they believe that monetary policy will continue to evolve as it has in the recent past. Prior 3 is the prior p.d.f. of agents who believe, a priori, that the reform will take place, and therefore has mean $\theta_{0}=0.0095$. This monthly growth rate of domestic credit is equal to $12 \%$ annually, and is about equal to the announced rate in the case of the Argentina reform. Recall that both countries were intending to fix their exchange rates at some point within two to four years, which constrains them to choice of a long-run $\theta$ smaller than the world inflation rate (in the absence of real growth).

Eq. (8) was estimated over the twelve-month pre-reform period, and the parameters of the resulting posterior p.d.f. were then used to formulate a data-based prior for $\gamma$ and $\sigma_{u}^{2}$ : the prior for $\gamma$ was 1.11, and the prior for $\sigma_{u}^{2}$ was 0.0035 . The estimation of (8) over the reform period was undertaken for two sets of prior assumptions: prior 1, a diffuse prior p.d.f., and prior 2, the data-based prior.

Unfortunately, only annual data are available for Chile's fiscal deficit and debt. Since the 'reform' began in Chile in 1978, this yields only four data points, and thus prohibited estimation of fiscal policy rules over the reform period. However, since Chile began the reform with a small fiscal surplus and since the real value of her debt declined over the reform period, we shall 
assume that the probability was one that Chile's fiscal policy satisfied condition (ii) for a feasible reform.

Given the posterior p.d.f.'s for $\theta$ and $\gamma$, we can calculate the measure of 'credibility', which was defined to be the subjective probability that $\left(\theta<\pi^{*}\right.$, $\gamma<1$ ), conditional on observations from the reform period. Since agents with a diffuse prior are influenced solely by data from the 'reform' period, the measure of credibility based on a diffuse prior provides a useful benchmark to which we can compare credibility based on other prior assumptions.

In the Argentine case, the reform starts out well. The probability that condition (i) for a feasible reform is satisfied $\left(\theta \leq \pi^{*}\right)$ remains above $50 \%$ for most of the first year, under the assumption of a diffuse prior. After April 1980 , credibility begins a dramatic and nearly monotonic decline, and is practically zero for the latter half of the reform period (see fig. 1). The probability of $\theta \leq \pi^{*}$ as assessed by the 'non-believers' and the 'believers' (priors 2 and 3 ) are very similar to each other, and to that for the diffuse prior. This reflects the fact that the growth rate of $D C$ during the year prior to the

ARGENTINA: PROBABILITY OF FEASIBLE MONETARY POLICY



Fig. 1 
reform was about $1.1 \%$ per month - quite close to the 'reform' value of $0.95 \%$ per month, combined with the effect of a large prior variance.

In Argentina, the probability that fiscal policy was 'feasible' $(\gamma<1)$, based on the diffuse prior, is as high as 67\% during the first year of the reform, but decreases over the course of the reform (see fig. 2). The probability of $\gamma<1$, as assessed by agents having a data-based prior, closely resembles the probability calculated under the assumption of a diffuse prior. This reflects the fact that the means of both the prior p.d.f. for $\gamma$ and of the diffuse posterior p.d.f. for $\gamma$ are greater than the critical value of one (i.e., the Argentine government did not undertake a reform of fiscal policy).

The 'credibility' of the reform has been defined as the subjective probability that both feasibility conditions are satisfied $\left(\theta<\pi^{*}, \gamma<1\right)$. The credibility measures for the two countries are graphed in figs. 3 and 4 . In the Chilean case, the credibility measure for the diffuse prior p.d.f. remains quite low for the first three years of the reform (less than a $20 \%$ probability of reform), but climbs dramatically beginning in February 1981, as the Central Bank drastically curtailed lending to the government, and caused a sharp decline in the money

ARGENTINA: PROBABILITY OF FEASIBLE FISCAL POLICY

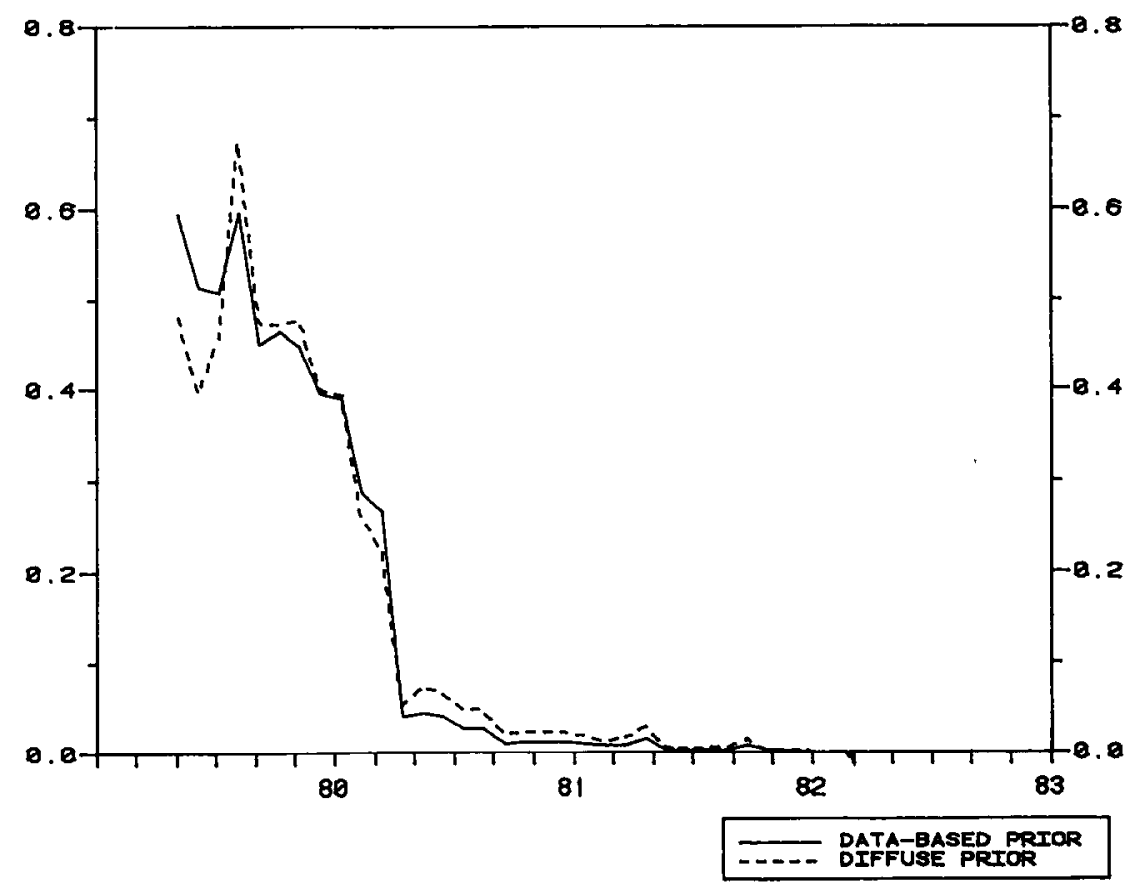

Fig. 2 


\section{CHILE: PROBABILITY OF CREDTBLE REFORM}

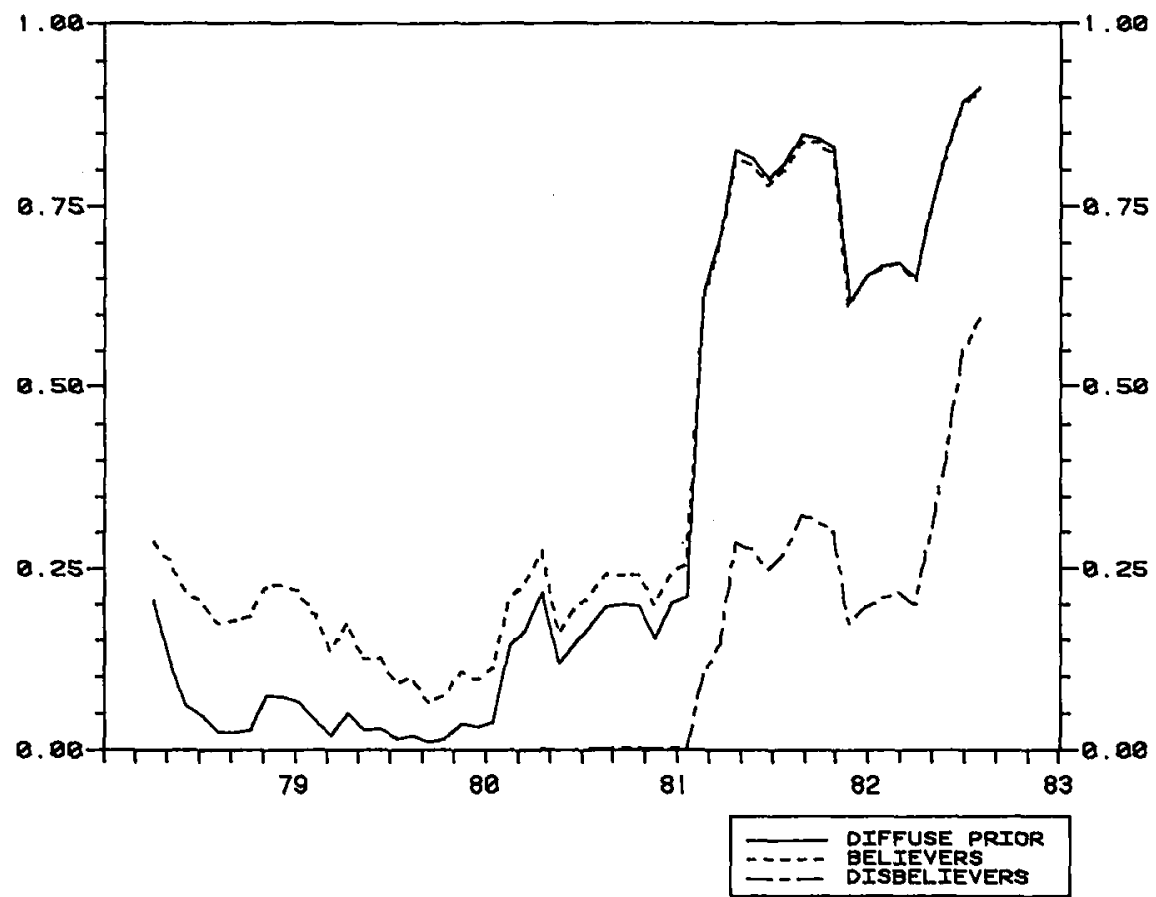

Fig. 3

supply. From this point, credibility rose to reach a level of 0.91 in July 1982. The prior for 'believers' in the reform (prior 3 ) results in a credibility measure of about 0.28 four months after the beginning of the reform, and climbs gradually to equal the measure for the diffuse prior. The credibility measure for the 'disbelievers' (prior 2) is almost zero until February 1981, and climbs thereafter to a level of 0.59 in June 1982.

The credibility measures for Argentina begin at a level of about 0.35 , and decline to a level of approximately zero in April of 1980, about fifteen months after the beginning of the reform. The unscheduled devaluation in February 1980 sparked a run on Argentina's reserves, as people reacted to the apparent abandonment of the 'reform' policy. The fact that the 'credibility' of the reform was so low at this point may help to explain the strength of agents' reactions to what was a small devaluation by the standards of Argentine economic history. The drain on reserves forced subsequent devaluations, and the abandonment of the exchange rate 'table'. 


\section{ARGENTINA: PROBABILITY OF CREDIBLE REFORM}

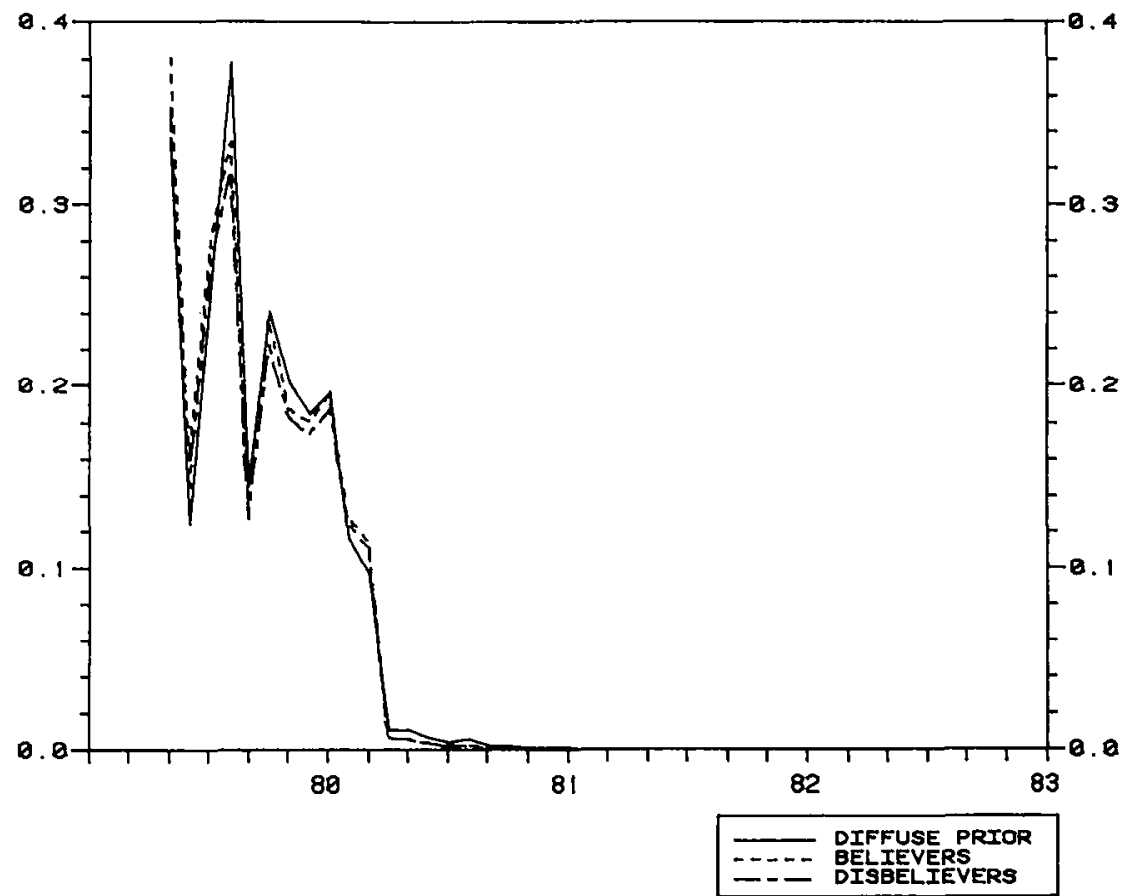

Fig. 4

\section{The effects of credibility}

The model of section 3 suggests that increases in credibility should, ceteris paribus, cause decreases in inflation and interest rates, and increases in reserves and real money demand. In particular, current inflation and interest rates should be functions of the posterior mean rate of expansion of domestic credit. In order to examine whether these relationships hold empirically, figs. 5 and 6 plot the monthly CPI inflation rate over the reform period together with the posterior mean for $\theta$ (the rate of growth of domestic credit under the assumption of a diffuse prior). Figs. 7 and 8 plot the posterior mean for $\theta$ against real and nominal interest rates.

In Chile, there appears to be a strong correlation between the posterior mean and inflation, i.e., the average of past growth rates of domestic credit appears to be a good predictor of inflation. Fig. 8, which plots the posterior mean against Chilean real and nominal interest rates, shows a close relation between the nominal rate and the posterior mean, with the nominal rate on average about $1 \frac{1}{2}$ percentage points higher than the average rate of growth of domestic 


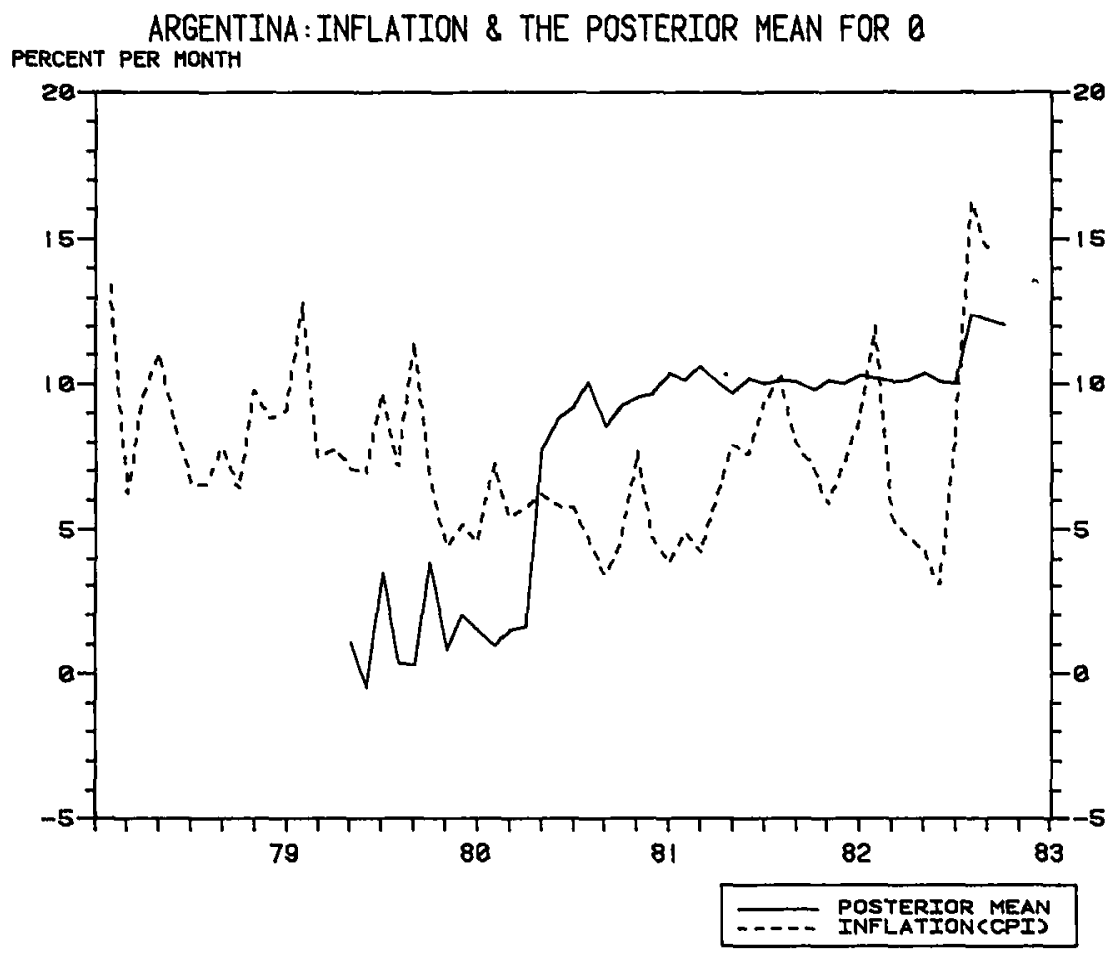

Fig. 5

credit. The ex post real rate is much more volatile than the nominal rate or the posterior mean.

In Argentina, neither inflation nor interest rates have the close comovement with the posterior mean that was observed in the Chilean case. But this is exactly what we would expect to happen if expectations and credibility do in fact depend on fiscal policy as well as monetary policy. To see this, suppose that the government adheres to the targeted monetary growth rate, but that fiscal policy is incompatible with reform, in the sense that condition (ii) for a feasible reform is not satisfied. Then, since the credibility of the reform is low, there is a positive probability that increased money growth will be used to finance the deficit. Hence agents will forecast higher future money growth and inflation: the result is higher current inflation and interest rates, even with a low current value of $\theta$.

While the Argentine 'reform' is accompanied by decreases in inflation and nominal interest rates, the rising real rate suggests that expectations of inflation exceeded the actual inflation rate. Figs. 5 and 7 illustrate that inflation rates and interest rates were relatively unaffected by the large jump in monetary 




CHILE:INFLATION AND THE POSTERIOR MEAN FOR $\theta$

Fig. 6

growth. Hence it seems likely that expectations of future inflation were formed on the basis of Argentina's 'incredible' fiscal policy and that the jump in domestic credit growth in April 1980 wasn't a 'surprise' at all.

Table 2 gives the correlations of the various measures of credibility with inflation rates, reserves, and monetary aggregates. The correlations calculated here cannot be construed as testing formally the hypothesis that credibility (or the lack thereof) 'cause' movements in inflation rates, reserves, and monetary aggregates, since none of these variables is strictly exogenous with respect to the credibility variable. However, significant correlations with the sign predicted by theory may be interpreted as evidence that credibility mattered to these reforms. The correlation between the Chilean CPI inflation rate and various measures of credibility are all negative, as theory predicts. Chile's foreign exchange reserves and all the real monetary aggregates are positively correlated with credibility, again, as the theory predicts. The various measures of credibility are all negatively correlated with nominal interest rates, but positively correlated with real interest rates. Apparently, increased credibility was associated with reductions in nominal interest rates via reduced inflationary expecta- 
PERCENT PER MONTH

ARGENTINA: INTEREST RATE AND THE POSTERIOR MEAN FOR $\theta$

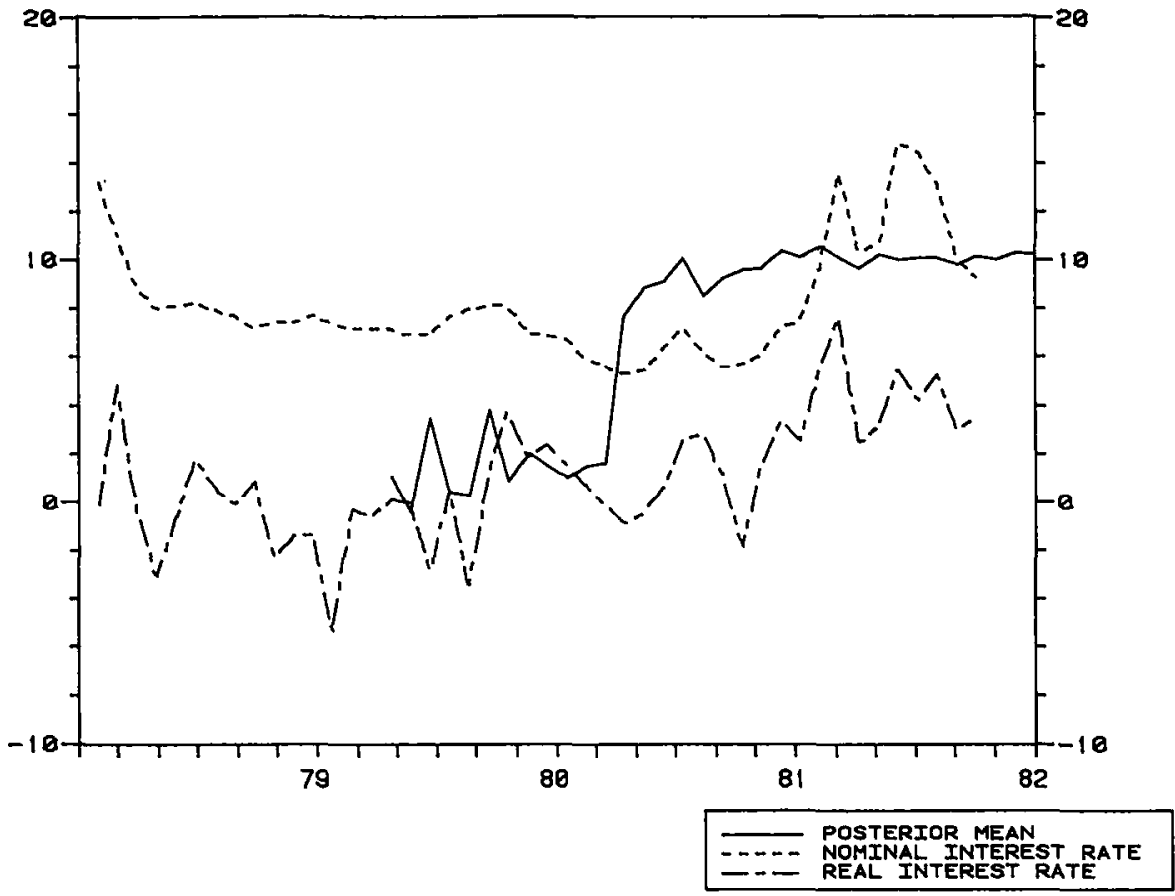

Fig. 7

tions. However, the reduction in anticipated inflation was smaller (in absolute value) than the actual reduction in inflation, causing an increase in the ex post real rates.

This effect is exactly what one would expect if agents are 'learning' over time about the government's policies. Because they are combining prior and sample information, agents will in general make serially correlated errors in prediction, until enough time has passed so they 'know' the true policy parameters (that is, the posterior p.d.f. on these parameters will be centered on the true value and have very low variance). These serially correlated errors are not evidence of agents' irrationality; they cannot be expected to forecast using the 'true' distributions for the policy parameters when they do not know them.

In Argentina, WPI inflation rates are negatively correlated with all measures of credibility, and with the feasibility of both monetary and fiscal policies individually. This lends support to the hypothesis that the credibility of both monetary and fiscal policies are important to the success of a reform. All of the credibility measures for Argentina have the predicted negative correlations with both nominal and real interest rates. High credibility reduces nominal 
CHILE: INTEREST RATES AND THE POSTERIOR MEAN FOR $\theta$ PERCENT PER MONTH

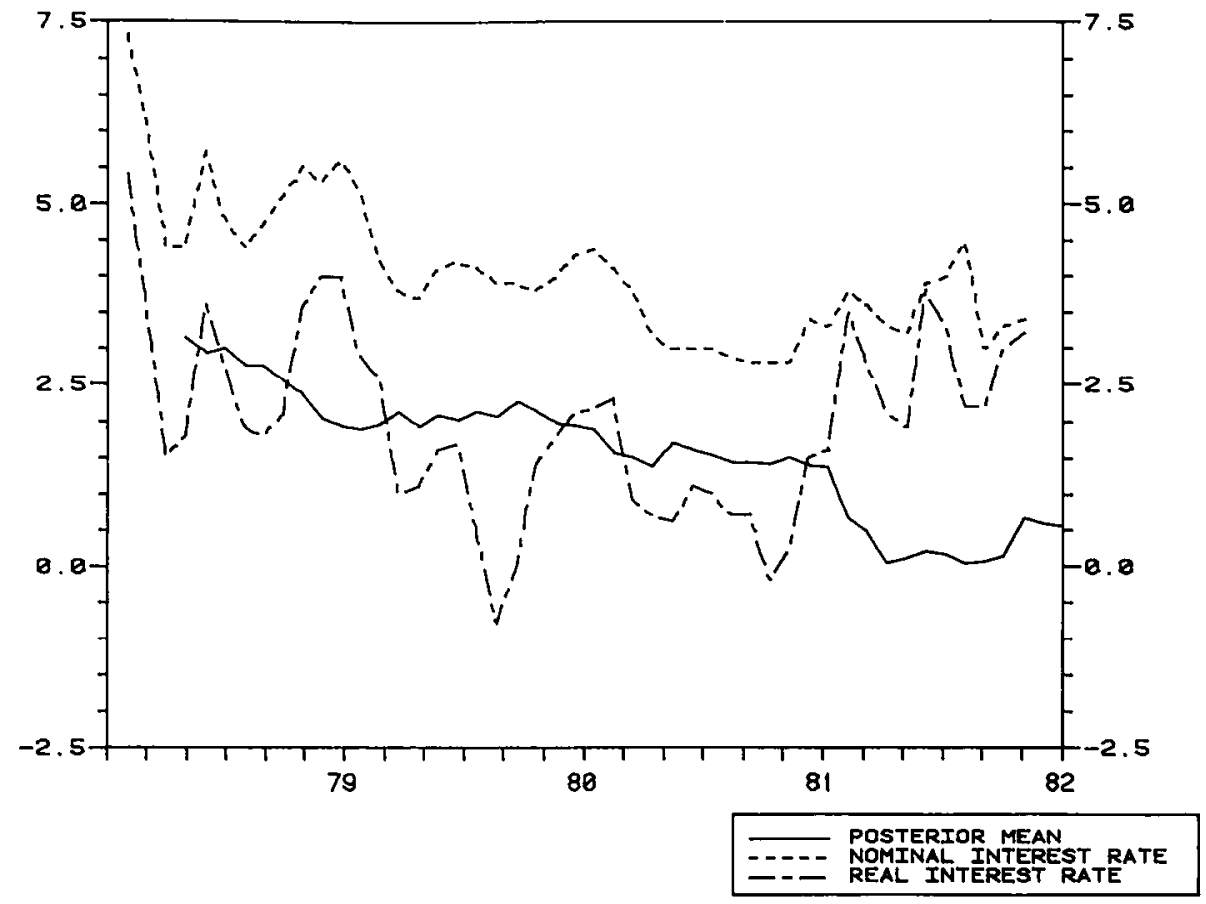

Fig. 8

rates by reducing inflationary expectations. In addition, high credibility also attracts foreign capital, and the result of foreign investment in Argentina during the initial two years of the reform was to reduce the real interest rate. To put the matter slightly differently - when the 'credibility' of a reform is high, lenders require less of a 'risk premium' and real rates will tend to be lower. Since Chile was relatively closed to capital flows, this also may help explain why high credibility was associated with lower real rates in Argentina, but higher real rates in Chile. In the case of Chile, barriers to capital flows prohibited arbitrage of real rates. Argentina's foreign exchange reserves are positively correlated with all measures of credibility, as theory predicts, despite the fact that the government's heavy external borrowing caused both low credibility and reserve inflows. Apparently, the speculative outflow due to reduced credibility more than offset the reserve inflows due to external borrowing.

Although it was not possible to frame a rigorous statistical test of the hypothesis that credibility influenced the outcomes of the Chilean and Argentina reforms, the correlations reported here provide evidence that credi- 
Table 2

Correlations between credibility and other economic variables.

\begin{tabular}{|c|c|c|c|c|c|c|c|}
\hline & \multicolumn{7}{|c|}{ Argentina } \\
\hline & \multicolumn{3}{|c|}{$\begin{array}{c}\text { Probability of feasible } \\
\text { monetary policy } \\
\text { Prior }\end{array}$} & \multicolumn{2}{|c|}{$\begin{array}{c}\text { Probability of feasible } \\
\text { fiscal policy } \\
\text { Prior }\end{array}$} & \multicolumn{2}{|c|}{$\begin{array}{l}\text { Credibility } \\
\text { Prior }\end{array}$} \\
\hline & $\operatorname{diff}^{a}$ & $\mathrm{NB}^{\mathrm{b}}$ & $\overline{B^{c}}$ & diff & $\mathrm{DB}^{\mathrm{d}}$ & diff & $\overline{\mathrm{DB}^{\mathrm{e}}}$ \\
\hline \multirow[t]{4}{*}{$\begin{array}{l}\text { CPI inflation } \\
\text { WPI inflation } \\
\text { Reserves (U.S.\$) } \\
\text { Real cash balances } \\
\text { Real M1 } \\
\text { Real M2 } \\
\text { Nominal interest rates } \\
\text { Real interest rates }\end{array}$} & $\begin{array}{r}-0.08 \\
-0.24 \\
0.11 \\
-0.04 \\
-0.79 \\
-0.80 \\
-0.44 \\
-0.55\end{array}$ & $\begin{array}{r}-0.08 \\
-0.24 \\
0.11 \\
-0.04 \\
-0.79 \\
-0.80 \\
-0.42 \\
-0.54\end{array}$ & $\begin{array}{r}-0.08 \\
-0.24 \\
0.11 \\
-0.04 \\
-0.79 \\
-0.79 \\
-0.42 \\
-0.53\end{array}$ & $\begin{array}{r}0.00 \\
-0.69 \\
0.07 \\
-0.12 \\
-0.75 \\
-0.76 \\
-0.50 \\
-0.53\end{array}$ & $\begin{array}{r}0.02 \\
-0.70 \\
0.05 \\
-0.13 \\
-0.79 \\
-0.76 \\
-0.54 \\
-0.55\end{array}$ & $\begin{array}{r}0.04 \\
-0.76 \\
0.07 \\
-0.15 \\
-0.68 \\
-0.69 \\
-0.38 \\
-0.49\end{array}$ & $\begin{array}{r}0.03 \\
-0.76 \\
0.08 \\
-0.15 \\
-0.69 \\
-0.69 \\
-0.40 \\
-0.51\end{array}$ \\
\hline & & \multicolumn{6}{|c|}{ Chile } \\
\hline & & & \multicolumn{4}{|c|}{ Credibility } & \\
\hline & & $\operatorname{diff}^{\mathrm{a}}$ & & & $\mathrm{NB}^{\mathrm{b}}$ & & $\mathrm{B}^{\mathrm{c}}$ \\
\hline $\begin{array}{l}\text { CPI inflation } \\
\text { WPI inflation } \\
\text { Reserves (U.S.\$) } \\
\text { Real cash balances } \\
\text { Real M1 } \\
\text { Real M2 } \\
\text { Nominal interest rates } \\
\text { Real interest rates }\end{array}$ & & $\begin{array}{r}-0.77 \\
0.18 \\
0.54 \\
0.71 \\
0.53 \\
0.89 \\
-0.34 \\
0.35\end{array}$ & & & $\begin{array}{r}-0.64 \\
0.18 \\
0.47 \\
0.58 \\
0.29 \\
0.83 \\
-0.23 \\
0.46\end{array}$ & & $\begin{array}{r}-0.78 \\
0.23 \\
0.30 \\
0.66 \\
0.45 \\
0.86 \\
-0.23 \\
0.39\end{array}$ \\
\hline
\end{tabular}

${ }^{a}$ Diffuse.

bNon-believers: data based prior with mean equal to the average value of $\theta$ over the twelve month pre-reform period.

'Believers: data based prior with mean equal to the reform value of $\theta$.

${ }^{`}$ Data-based prior.

'Data-based priors: the data-based prior for fiscal policy, and the data-based priors for monetary policy (both data-based priors yield the same correlations).

bility was in fact important. Our results support the hypothesis that agents do in fact look at both monetary and fiscal variables in assessing the likelihood that a true 'reform' is taking place. Particularly encouraging are the correlations between credibility and interest rates, inflation rates, and reserves.

\section{Conclusions}

The purpose of this work was to develop a theory of the way agents form expectations about the future course of government policy in a world where the 
parameters of the policy rules are not known with certainty. While this work was motivated by, and applied to, the Chilean and Argentine exchange reforms of the late 1970's, the theory developed here is quite general, and could be applied to any situation where agents have an incentive to learn about a policy.

Agents learn in a Bayesian fashion about the true parameters of government policy. We examined the implications for the posterior parameter estimates of various assumptions about the state of agents' prior beliefs. 'Credibility' of government policies was defined to be the subjective probability, based on prior beliefs and data from the reform period, that the government was in fact following the announced 'reform' policy rule. Economic theory suggests that high credibility of a monetary reform should result in reduced inflationary expectations, and therefore should cause reductions in current inflation rates and interest rates, an increase in reserves via increases in real money demand, and decreases in speculative outflows.

It was shown that credibility of a monetary reform depends on both monetary and fiscal polices, since a large fiscal deficit is incompatible, in the long run, with a low rate of money creation. If it is likely that the real value of the government debt is following an explosive path, then agents will realize that it is unlikely that the monetary reform can be sustained. They will therefore assign positive probability to the event that the monetary reform will be abandoned, and will therefore forecast higher future rates of monetary growth.

The effect of this lack of credibility is to increase expectations of future inflation, which tends to increase today's inflation and interest rates, and reduces real money demand. Hence, we expect to observe negative correlations between 'credibility' and inflation and interest rates, and a positive correlation between 'credibility' and real cash balances and reserves. These correlations were, in fact, found for most of the measures of credibility calculated. In addition, the results for Argentina support the hypothesis that both monetary and fiscal policies matter to the success of a monetary or exchange reform.

The correlations reported here cannot be interpreted as providing a clean statistical test of the hypothesis that credibility had an important effect on the outcome of these reforms. In order to test more formally the hypothesis that credibility is important, it would be necessary to construct a complete structural model, or to conduct a cross-sectional, multi-country study, similar in spirit to Lucas (1973). Such a study is, however, beyond the scope of this work, but seems to be the logical next step in the investigation of the importance of 'credibility' to the outcome of reforms.

The policy implications of this work are quite clear. While agents' priors are likely to be the result of 'history' and therefore not under the direct control of the current administration, a government interested in reducing inflation by means of a monetary reform is not completely at the mercy of its country's economic history. The theory suggests and the empirical evidence supports the 
hypothesis that close adherence to a policy of reducing the monetary growth rate combined with a low fiscal deficit can result in dramatic reductions in inflation. We have shown, both theoretically and empirically, that is insufficient to announce and maintain restrictive exchange rate and monetary policies. Agents will also look at fiscal policy in their attempt to determine whether the 'reform' can be sustained. If fiscal policy is incompatible with the 'reform' monetary policy, agents will attach positive probability to the event that the reform will be abandoned in the future. The result will be an increase in inflationary expectations, and the 'expectations bonus' the government hoped to gain by announcement of the reform will be lost.

\section{References}

Boletin Mensual, various issues (Banco Central de Chile, Santiago).

Flood, Robert P. and Peter M. Garber, 1980, An economic theory of monetary reform, Journal of Political Economy 88, 24-58.

Indicadores de Coyuntura, various issues (Fundacion de Investigaciones Economicas Latinoamericanas, Buenos Aires).

International Financial Statistics (International Monetary Fund, Washington, DC).

La Haye, Laura, 1980, Inflation and currency reform: A study of the effects of anticipated policy switching, Unpublished Ph.D. dissertation (University of Chicago, Chicago, IL).

Lucas, Robert E., Jr., 1973, Some international evidence on output-inflation tradeoffs, American Economic Review 63, 326-334.

Rodriquez, Carlos A., 1979, The Argentine stabilization plan of December 20, Working paper no. 5, July (C.E.M.A., Buenos Aires).

Sargent, Thomas J., 1981a, The end of four big inflations, NBER working paper.

Sargent, Thomas J., 1981 b, Stopping moderate inflations: The methods of Poincarré and Thatcher, NBER working paper.

Sargent, Thomas J. and Neil Wallace, 1981, Some unpleasant monetarist arithmetic, Federal Reserve Bank of Minneapolis Quarterly Review 117, 1-17.

Taylor, John B., 1980, An econometric business cycle model with rational expectations: Policy evaluation results, Working paper, May (Yale University, New Haven, CT).

Van Wijnbergen, Sweder, 1983, Fiscal deficits, high real interest rates and sustainability of preannounced crawling peg regimes: A Bayesian analysis of Argentina: 1978-1981, Unpublished working paper, June (World Bank, Washington, DC).

Zellner, Arnold A., 1971, An introduction to Bayesian inference in econometrics (Wiley, New York).

Zellner, Arnold A., 1981, Bayesian regression analysis package (BRAP) (University of Chicago, Chicago, IL). 